\title{
O MOVIMENTO DE EDUCAÇÃO DE BASE NO BRASIL: UM DIÁLOGO COM A NOVA BASE NACIONAL COMUM CURRICULAR
}

Jeanny Meiry Sombra Silva*

\section{RESUMO}

O MEB teve em sua essência o ideal de construção de uma cultura nacional, popular e democrática, por meio de atividades conscientizadoras junto às classes populares. Para isso, desenvolveu diferentes ações educativas, dentre elas a alfabetização de adultos. O Brasil ainda apresenta um alto índice de analfabetismo. Buscando sua inserção na escolarização, muitos adultos buscam a EJA. Diante desse cenário, o artigo discute como a nova BNCC trata a educação e o currículo para esse contingente.

Palavras-chave: Movimento de Educação de Base; Educação de Jovens e Adultos; alfabetização de adultos; Base Nacional Comum Curricular.

\begin{abstract}
The MEB had in its essence the ideal of building a national culture, popular and democratic, through awareness activities among the popular classes. For this, it developed different educational actions, among them adult literacy. Brazil still has a high rate of illiteracy. Looking for their insertion in schooling, many adults seek out the EJA. Given this scenario, the article discusses how the new BNCC treats education and curriculum for this contingent.
\end{abstract}

Key-Words: Basic Education Movement; Youth and Adult Education; Adult Literacy; National Common Curricular Base

O Movimento de Educação de Base (MEB) foi criado pela CNBB - Conferência Nacional dos Bispos do Brasil, em 1961, com o intuito de desenvolver um programa de educação às populações das áreas subdesenvolvidas do Norte, Nordeste e Centro-Oeste do País por meio de escolas radiofônicas.

Documentos legais do MEB explicitam: "Entende-se como educação de base o conjunto dos ensinamentos destinados a promover a valorização do homem e o soerguimento das comunidades" (MEB, 1965, p. 19). Visando promover a valorização humana em sociedade o Programa propunha ações de alfabetização, formação moral e cívica, educação sanitária, iniciação profissional, sobretudo agrícola e promoção social.

\footnotetext{
* Doutoranda do programa de Psicologia da Educação da PUC/SP.
} 
O Brasil viveu momentos de intensa mobilização cultural e política, no final dos anos 50 e início dos anos 60. Nesse período, difundiram-se as ideias de educação popular, acompanhando a democratização da escolarização básica. Estudantes e intelectuais desenvolviam novas perspectivas de cultura e educação junto a grupos populares, por meio de diferentes instituições e com graus variáveis de ligação com o Estado. Destacaram-se, além do MEB, outros movimentos significativos, nessa fração da história brasileira: A união Nacional dos Estudantes (UNE) discutia questões nacionais e as perspectivas de transformação que mobilizavam o país. O Centro Popular de Cultura Popular (CPC), ligado a UNE, foi criado em 1961 e se espalhou pelo país, travando contato com bases universitárias, operárias e camponesas. O Movimento de Cultura Popular (MCP), no qual Paulo Freire desenvolveu o Projeto de Educação de Adultos, viabilizou sua experiência de Angicos. Esta experiência projetou Paulo Freire em plano nacional, para a realização do PNA - Programa Nacional de Alfabetização.

Entretanto, toda essa atividade foi suspensa por ocasião do golpe militar, quando muitos dos promotores da educação popular e da alfabetização passaram a sofrer repressão. Persistiram algumas iniciativas, desenvolvidas frequentemente em igrejas, associações de moradores, organizações de base local e outros espaços comunitários, influenciadas pelas concepções da educação popular com intencionalidade política.

$\mathrm{Na}$ esteira do MEB e de todos os movimentos desse período estava o ideal de construção de uma cultura nacional, popular e democrática, por meio de atividades conscientizadoras junto às classes populares (PEREIRA;PEREIRA, 2010). Um esforço comum a todos esses movimentos era implementar ações de combate ao analfabetismo, tendo consciência de que "o analfabetismo não é uma chaga, nem uma erva daninha a ser arrancada, nem tampouco uma enfermidade, mas uma das expressões concretas de uma realidade social injusta." (FREIRE, 1981, p. 15).

\section{Do MEB à EJA: compartilhando os interesses na alfabetização e educação de adultos}

$\mathrm{Na}$ época do surgimento do MEB, o Brasil registrava 15,9 milhões de analfabetos (entendidos como pessoas de 15 anos ou mais que se declaram incapazes de ler e escrever um 
bilhete simples), um percentual de $39,6 \%$ sobre o total da população ${ }^{1}$. Para o MEB a alfabetização era apenas um dos conteúdos da educação de base e não o objeto principal da ação do movimento. Contudo, a constatação dos altíssimos índices de analfabetismo entre as populações adultas das regiões ditas "atrasadas" e a correlação estabelecida entre o analfabetismo e o nível de desenvolvimento econômico, passaram a apontar o analfabetismo como a expressão mais aguda do atraso dessas regiões e países, o que forçou o movimento a intensificar ações de ensino para alfabetização.

\begin{abstract}
As condições infra-humanas em que vivem milhões de brasileiros, principalmente de zona rural e suburbana, constituem grave problema social e reclamam a ocorrência de todas as forças na sua solução. Devemos colocar como um dos mais importantes objetivos a educação do povo. Educação como instrumento de conscientização desse grande contingente humano marginal ainda. Educação que ajude o povo a se integrar na vida nacional. Um povo somente chega à sua maioridade quando todos possuem educação suficiente para serem responsáveis e membros produtivos da comunidade. (MEB, [19-], pg. 2)
\end{abstract}

O mapa do analfabetismo brasileiro, segundo o INEP, tem diminuído. No entanto, o último censo realizado pelo $\mathrm{IBGE}^{2}$ evidenciou que esses números ainda são muito expressivos. O Brasil ainda tem cerca de 11,8 milhões de analfabetos, o que corresponde a 7,2\% da população de 15 anos ou mais. A taxa indica que o Brasil não conseguiu alcançar uma das metas intermediárias estabelecidas pelo Plano Nacional de Educação (PNE) em relação à alfabetização da população com 15 anos ou mais. A meta 9 do PNE determinava a redução do analfabetismo a $6,5 \%$ até 2015 , o que não aconteceu.

Os dados do INEP ainda indicam que grande parte dos analfabetos iniciou e desistiu de continuar os estudos e que a maior concentração de analfabetos está na população de 60 anos ou mais. Quanto mais baixa a renda familiar, maior é o índice de analfabetismo. No meio rural brasileiro, a taxa de analfabetismo é três vezes superior a da população urbana, e o contraste é ainda maior na região nordeste.

\footnotetext{
1 Fonte: MEC/Inep. Disponível em http://portal.inep.gov.br/documents/186968/485745/Mapa+do+analfabetismo+no+Brasil/a53ac9ee-c0c0-4727b216-035c65c45e1b?version $=1.3$

${ }^{2}$ Fonte: IBGE, Diretoria de Pesquisas, Coordenação de Trabalho e Rendimento, Pesquisa Nacional por Amostra de Domicílios Contínua 2016.
} 
Paulo Freire chama a atenção para posição astuta ou ingênua que omite causalidade política e deixa de denunciar o discurso ideológico que se refere aos analfabetos como seres incapazes, indolentes ou preguiçosos: "ninguém é analfabeto por eleição, mas como consequência das condições objetivas em que se encontra. Em certas circunstâncias, o analfabeto é o homem que não necessita ler, em outras, é aquele ou aquela a quem foi negado o direito de ler." (FREIRE, 1981, p. 15). Pesquisas consideram (HADDAD; DI PIERRO, 2000) que um contingente desta população de analfabetos tenta, ao longo de sua vida, se inserir no mundo escolarizado, recorrendo à educação de jovens e adultos (EJA).

A atual LDB (artigo 37, seção V) estabelece que a educação de jovens e adultos é destinada àqueles que não tiveram acesso ou continuidade de estudos no ensino fundamental e médio na idade própria. $\mathrm{Na}$ LDB, a EJA é considerada uma modalidade de ensino da educação regular.

Russel e Silva (2012) realizaram um estudo do perfil do aluno da EJA e concluíram que a Educação de Jovens e Adultos conta com um público muito diverso. Dentro da mesma sala de aula, há pessoas da terceira idade, adultos de 40 anos ou mais, jovens de 20 a 24 anos e adolescentes de 14 a 17 anos. A modalidade, ao longo dos anos, vem passando por um processo de 'juvenilização', atendendo até mesmo um público que deveria estar matriculado no ensino regular. Legalmente, a idade mínima para ingresso em turmas de EJA é de 15 anos no ensino fundamental e 18 no médio.

Mesmo havendo uma variação etária no público da EJA, ainda há, no Brasil, uma grande população de pessoas adultas estudando nessa modalidade. Em 2016, de acordo com o INEP, o total de alunos matriculados na EJA em todo o Brasil foi de 3.482.174. Dessa população, 660.353 pessoas têm mais de quarenta anos de idade, ou seja, 18,96\%. A grande maioria está cursando as séries iniciais do Ensino Fundamental.

Independente da idade há características comuns a esses alunos,

Apesar da grande heterogeneidade, um traço bastante comum do aluno da EJA é sua condição socioeconômica. Os homens, mulheres, jovens, adultos ou idosos que buscam a escola tardiamente pertencem, de maneira geral, a uma mesma classe social: são pessoas com baixo poder aquisitivo. Trata-se de um indivíduo que historicamente vem sendo excluído, quer pela impossibilidade de acesso à escolarização, quer pela exclusão da educação regular. (RUSSEL;SILVA, 2012, p. 115) 
A compreensão desta realidade de exclusão social levou o MEB, bem como os outros movimentos de base popular contemporâneos, a reconhecer o analfabetismo, assim como a educação de um modo geral, como uma questão não só pedagógica, mas também social e política. Na concepção freireana (1998), educar a favor dos pobres é educar para a transformação da sociedade geradora da pobreza. Enfatizavam, portanto, esses movimentos, a função transformadora que a escola deve ter para cada indivíduo que passa por ela, que precisa ser modificado não apenas pela soma de conhecimentos, mas pelo uso que fará deles, pelo poder transformador que alcançará ao aproximar-se da língua e da cultura da classe que o domina, podendo assim interagir com ela para melhorar sua própria realidade, reinventando-se.

Tal processo só será possível quando a escola se reconhecer como espaço de transformação, educando seus alunos por meio de uma pedagogia crítica, que reconheça o caráter político do ato educativo e que respeite e compreenda os sonhos e as expectativas do aluno a partir de uma proposta pedagógica e conteúdos programáticos condizentes com sua realidade e seus interesses.

Mas como as escolas que atendem a EJA trabalham os conteúdos curriculares para esses alunos? Nas escolas públicas do Estado de São Paulo, tanto na rede estadual quanto municipal, há um currículo organizado para a educação básica, mas nunca houve um currículo específico para essa modalidade de ensino. (RUSSEL; SILVA, 2012). Havia expectativas, por parte de educadores, de que a nova base comum curricular apresenta-se algumas diretrizes.

\section{A nova base comum curricular, exclusão da EJA?}

A nova Base Nacional Comum Curricular (BNCC) é um documento de caráter normativo que define o conjunto orgânico e progressivo de aprendizagens essenciais que todos os alunos devem desenvolver ao longo das etapas e modalidades da Educação Básica. Conforme definido na LDBEN 9.394/96, a Base deve nortear os currículos dos sistemas e redes de ensino das Unidades Federativas, como também as propostas pedagógicas de todas as escolas públicas e privadas de Educação Infantil, Ensino Fundamental e Ensino Médio, em todo o Brasil. 
O que muda com a nova Base? Com ela, redes de ensino e instituições escolares públicas e particulares passam a ter uma referência nacional obrigatória para a elaboração ou adequação de seus currículos e propostas pedagógicas.

A Educação de Jovens e Adultos (EJA), assim como as outras modalidades da educação básica, também terá como referência para elaboração de seu currículo a Base Nacional Comum Curricular (BNCC). Contudo, o documento não dá orientações específicas para a modalidade. Propõe princípios comuns e gerais a todas as modalidades da educação, tais como "contextualizar os conteúdos dos componentes curriculares, identificando estratégias para apresentá-los, representá-los, exemplificá-los, conectá-los e torná-los significativos, com base na realidade do lugar e do tempo nos quais as aprendizagens estão situadas.” (BNCC, 2018, p. 16).

Após a explanação dos diferentes princípios, o documento considera que ficará a cargo dos estados e municípios realizar as devidas adequações às realidades locais. É neste item que se encontra a única menção feita à EJA em todo o documento:

Essas decisões precisam, igualmente, ser consideradas na organização de currículos e propostas adequados às diferentes modalidades de ensino (Educação Especial, Educação de Jovens e Adultos, Educação do Campo, Educação Escolar Indígena, Educação Escolar Quilombola, Educação a Distância), atendendo-se às orientações das Diretrizes Curriculares Nacionais. No caso da Educação Escolar Indígena, por exemplo, isso significa assegurar competências específicas com base nos princípios da coletividade, reciprocidade, integralidade, espiritualidade e alteridade indígena, a serem desenvolvidas a partir de suas culturas tradicionais reconhecidas nos currículos dos sistemas de ensino e propostas pedagógicas das instituições escolares. Significa também, em uma perspectiva intercultural, considerar seus projetos educativos, suas cosmologias, suas lógicas, seus valores e princípios pedagógicos próprios (em consonância com a Constituição Federal, com as Diretrizes Internacionais da OIT - Convenção 169 e com documentos da ONU e Unesco sobre os direitos indígenas) e suas referências específicas, tais como: construir currículos interculturais, diferenciados e bilíngues, seus sistemas próprios de ensino e aprendizagem, tanto dos conteúdos universais quanto dos conhecimentos indígenas, bem como o ensino da língua indígena como primeira língua. (BNCC, 2018, p. 17)

Destacam-se, nesta citação, informações mais detalhadas apenas sobre como proceder em relação a propostas de ensino para a modalidade de educação indígena. Os termos "jovens e adultos" aparecem vinte e oito vezes ao longo de todo o documento, sempre de maneira genérica. 
Há muito se discute no meio educacional a necessidade de um currículo para EJA. Nesse sentido, diversos programas e políticas educacionais (em diferentes Estados da federação) apresentaram propostas curriculares, mas nenhuma se consolidou em um currículo nacional. $\mathrm{Na}$ figura 1 é possível visualizar o organograma da última proposta apresentada pelo MEC em 2002.

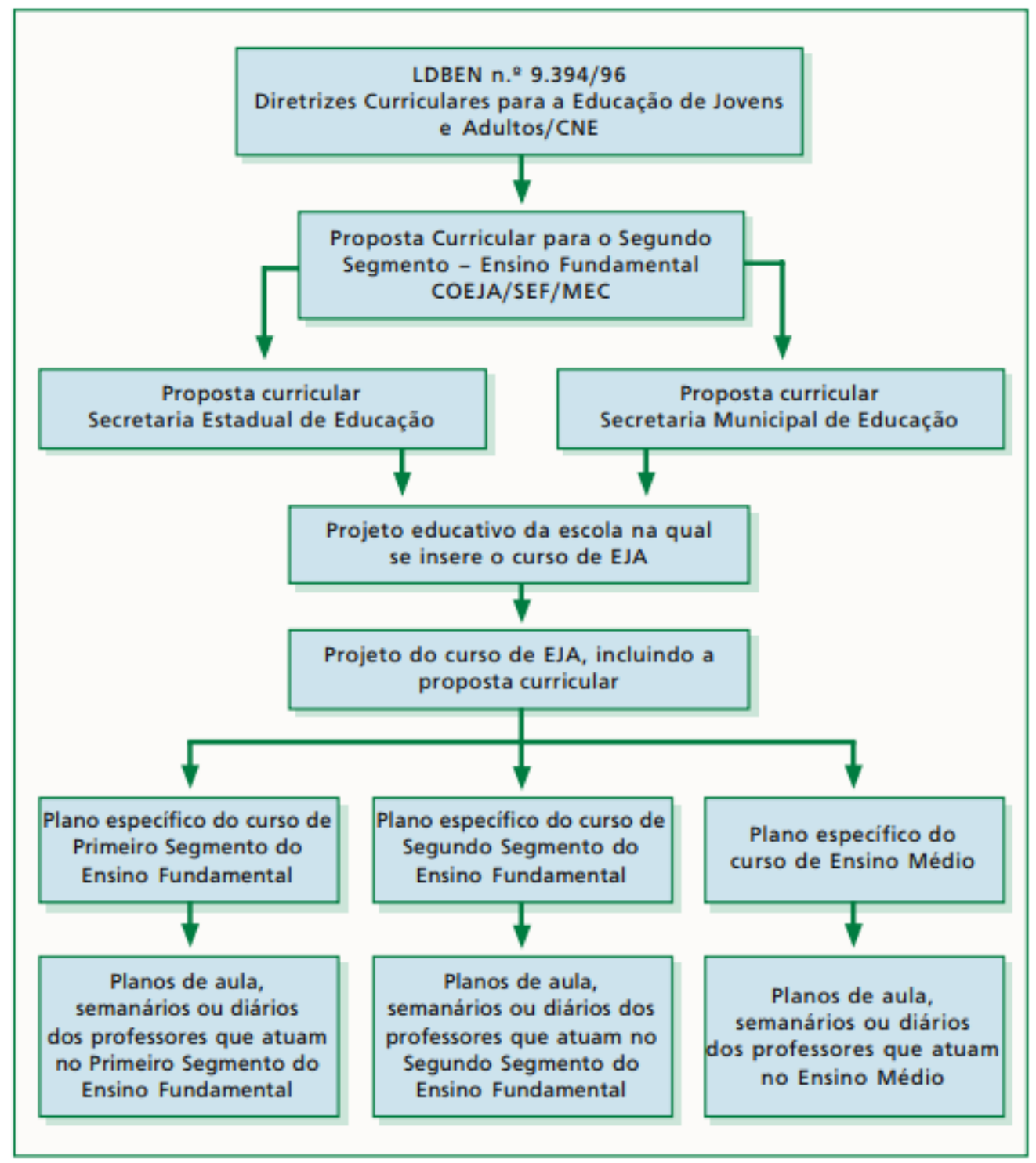

Figura 1 (BRASIL, 2002, p. 79).

Desde então, a modalidade da EJA tem utilizado diferentes documentos legais como referencia: as Diretrizes Curriculares Nacionais, que foram publicadas em 2000, documento que passa a definir a EJA como modalidade da Educação Básica e como direito do cidadão, 
afastando-se da ideia de compensação e suprimento e assumindo a de reparação, equidade e qualificação. Posteriormente, em 2010, foram publicadas as diretrizes operacionais, que tratam da organização da modalidade dentro da educação básica, bem como da duração dos cursos, idade mínima para ingresso e a educação a distância na modalidade. Há também os Parâmetros Curriculares Nacionais - PCN da modalidade. Esses elementos são importantes para se discutir currículo, e orientações curriculares, mas não se consubstanciam em um currículo.

Por não se ter um currículo da modalidade, o maior definidor dos conteúdos da EJA acaba sendo o livro didático. A modalidade entrou no Plano Nacional do Livro Didático (PNLD) em 2009. A escolha do material produzido pelas editoras fica a critério de cada escola, não há avaliação da pertinência e relevância pedagógica, justamente por não se ter um currículo que o regulamente.

Há uma especificidade de aprendizagem nessa modalidade. Por atender um público muito heterogêneo e distinto do ensino regular, torna-se necessária adaptação tanto dos conteúdos abordados quanto da maneira de tratá-los em sala de aula (OLIVEIRA, 1999).

Os conteúdos devem estar de acordo com a realidade dos alunos, respeitando os seus conhecimentos prévios, que não são os mesmos dos alunos do regular. O resultado de currículos ou abordagem inadequados na EJA pode ser a evasão. A esse respeito, Freire, desde a época do Movimento de Cultura Popular (MCP) já advertia:

\footnotetext{
Que podem um trabalhador camponês ou um trabalhador urbano retirar de positivo para seu que-fazer no mundo, para compreender, criticamente, a situação concreta em que se acham, através de um trabalho de alfabetização em que se lhe diz, adocidamente, que 'asa é da ave' ou 'Eva viu a uva'? Mais do que escrever e ler que 'a asa é da ave', os alfabetizandos adultos necessitam perceber a necessidade de um outro aprendizado: o de escrever a sua vida, o de ler a sua realidade, o que não será possível se não tomam a história nas mãos para, fazendo-a, por ela serem feitos e refeitos. (FREIRE, 1981, p. 11)
}

Processo similar ocorre ainda hoje nas salas de aula da EJA, muitas vezes, os professores recorrem aos mesmos materiais e livros didáticos utilizados com alunos do ensino regular. $\mathrm{O}$ resultado, quase sempre, é uma proposta infantilizada, com conteúdos inadequados ou que apenas tangenciam as necessidades reais de aprendizagem dos adultos da EJA. 
É fato que nesse aspecto a preparação metodológica e didática do professor é de suma importância. A ele cabe o importante papel de selecionar conteúdos pertinentes para a modalidade, não somente pensando na faixa etária, mas pensando no currículo e na proposta pedagógica da escola. Conforme disposto no documento Parâmetros Curriculares Nacionais da EJA (figura 1), fica a cargo do professor desenvolver, em seu plano de ensino e plano de aula, o planejamento didático dos conteúdos e estratégias de ensino.

Mas será que o professor da EJA recebe adequada formação profissional para orientálo nessa empreitada? Ou, como questiona Vasconcelos (2012, p. 17)

Considerando que a aprendizagem é um processo contínuo e individual, ocorrendo de diferentes maneiras em função do estágio de desenvolvimento de cada indivíduo, e que os cursos de licenciatura formam professores apenas para a educação infantil e básica, como estará o professor dessas turmas enfrentando tal desafio?

Em depoimento, uma professora de língua portuguesa da EJA que dá aula para alunos do Ensino Fundamental II (correspondente ao segundo segmento) declarou:

A gente tenta adaptar, usamos o livro didático (didático) para hora de ensinar gramática. Nessa hora até dá, mas ai, tem a leitura dos textos, não dá para usar uma fábula ou conto da chapeuzinho vermelho com eles. Nessa hora, a gente precisa procurar outros textos, elaborar outras atividades, montar sequência didática ... eu já tentei até montar uma apostila específica para esses alunos. Mas daí tem que tirar dezenas de cópias, fica caro. (RUSSEL; SILVA, 2012, p. 117)

Percebe-se nesse depoimento uma tensão entre o tempo disponível e a tarefa de tratar os conteúdos propostos para o Ensino Fundamental - em especial os contemplados nos livros didáticos. Resta a professora, portanto, realizar reduções e simplificações curriculares, que certamente trazem um grande empobrecimento ao processo de aprendizagem.

\section{BNCC: onde está o discurso de educação reparadora, qualificadora e equalizadora tão presente nos movimentos de base e nas diretrizes da EJA?}

Para os autores da nova BNCC, o fato da EJA não contar com um tópico específico na base não reduz a importância da modalidade, mas permite que as escolas mantenham flexibilidade em seus planejamentos curriculares. Contudo, conforme se discutiu nesse artigo: 
a perspectiva de conferir à escola a responsabilidade de elaborar e desenvolver seu projeto educativo não deve significar omissão das instâncias governamentais, tanto nos aspectos administrativo e financeiro como do ponto de vista pedagógico. Não contemplar a EJA na BNCC não seria uma omissão?

A EJA é uma modalidade da educação básica, mas ao tratá-la de maneira genérica, desarticulada de suas especificidades, a BCNN diluiu a importante discussão sobre um currículo específico. Não incorporar a EJA na elaboração da nova base, aparentemente pode parecer uma questão irrelevante, mas evidencia um pensamento ideológico que precisa ser melhor analisado.

Resta às equipes escolares de EJA conhecer, discutir e aprofundar as orientações disponíveis na BNCC, estabelecendo princípios para uma atuação coerente com sua realidade. Da mesma forma, o conhecimento das especificidades da educação de jovens e adultos e o registro das ações desenvolvidas por essa modalidade da Educação Básica precisam constituir uma preocupação das secretarias de educação das diferentes instâncias do nosso sistema educacional.

Pensar nos princípios do MEB, e de outros movimentos de base, ao ler a nova BNCC foi um exercício profícuo que permitiu refletir no quanto é necessário avançar para constituir uma educação reparadora, qualificadora e equalizadora. Ainda há um longo caminho a se percorrer para extinguir o analfabetismo nacional.

É necessário que a escola assuma a função reparadora de uma realidade injusta, que não deu oportunidade nem direito de escolarização a tantas pessoas. Ela deve também contemplar o aspecto equalizador, possibilitando novas inserções no mundo do trabalho, na vida social, nos espaços de estética e na abertura de canais de participação. Mas há ainda outra função a ser desempenhada: a qualificadora, com apelo à formação permanente, voltada para a solidariedade, a igualdade e a diversidade. (BRASIL, 2002).

\section{REFERÊNCIAS}

BRASIL. Ministério de Educação e Cultura. Parecer CEB 11/2000. Diretrizes curriculares nacionais para a educação de jovens e adultos. Brasília: MEC, 2000. 
BRASIL. Ministério da Educação. Secretaria de Educação Fundamental. Proposta Curricular para a educação de jovens e adultos: segundo segmento do ensino fundamental: 5a a 8a série: introdução / Secretaria de Educação Fundamental, 2002. Disponível em http://portal.mec.gov.br/secad/arquivos/pdf/eja_livro_01.pdf Acesso em 15/04/2018 BRASIL. Ministério da Educação; Secretaria de Educação Básica; Conselho Nacional de Educação; Câmara de Educação Básica. Base Nacional Comum Curricular. Brasília: MEC, 2018. Disponível em: http://basenacionalcomum.mec.gov.br/wpcontent/uploads/2018/04/BNCC_19mar2018_versaofinal.pdf Acesso em 16/04/2018.

FÁVERO, Osmar. Uma pedagogia da participação popular; análise da prática pedagógica do MEB Movimento de Educação de Base, 1961-1966. Campinas: Autores Associados, 2006.

FREIRE, P. Ação cultural para a liberdade. $5^{\mathrm{a}}$ ed. Rio de Janeiro: Paz e Terra, 1981. . Pedagogia do Oprimido. $25^{\text {a }}$ ed. Rio de Janeiro: Paz e Terra, 1998.

HADDAD, Sérgio; DI PIERRO, Maria C. Escolarização de jovens e adultos. Revista brasileira de Educação. São Paulo, n.14, maio-ago. 2000, pp.108-130.

MEB. Fundamentação do programa para 1965 - 1. ${ }^{\mathrm{a}}$ parte: Estudos Sociais, 1.1 Cultura. Rio de Janeiro: MEB, 1965. Disponível em http://www4.pucsp.br/cedic/meb/o-meb.html Acesso em $13 / 04 / 2018$.

OLIVEIRA, Marta Kohl. Jovens e adultos como sujeitos de conhecimento e aprendizagem. Revista Brasileira de Educação, no 12, 1999.

PEREIRA, D. \& PEREIRA, E. Revisitando a história da educação popular no Brasil: em busca de um outro mundo possível. Revista Histedbr On-line, Campinas, n.40, p. 72- 89, dez.2010.

RUSSEL, Gisele M.; SILVA, Jeanny Meiry S. O aluno idoso da EJA e dos cursos livres para a terceira idade: encontros e desencontros. In. VASCONCELOS, Maria Lucia M. C.; BRITO, Regina (orgs.) Educação para a terceira idade. São Paulo: edições Loyola, 2012.

VASCONCELOS, Maria Lucia M. C. A terceira idade volta à escola: quem está preparada para recebe-la? In. VASCONCELOS, Maria Lucia M. C.; BRITO, Regina (orgs.) Educação para a terceira idade. São Paulo: edições Loyola, 2012. 